\title{
Green Economy as an Object of State Regulation of Sustainable Development
}

\author{
Nina Gostieva ${ }^{1,{ }^{*}, \text { Elena } \text { Kazarinova }^{1}, \text { Ekaterina Samarina }}{ }^{1}$, and Anna Balabanova $^{2}$ \\ ${ }^{1}$ Plekhanov Russian University of Economics, Department of Political Economy and \\ History of Economic Science, 117997, Moscow, 36 Stremyanny lane, Russia \\ ${ }^{2}$ Russian Academy of Entrepreneurship, Rector, 109544 15, Malaya Andronievskaya st., \\ Moscow, Russia
}

\begin{abstract}
In the past two years, the idea of a green economy has been widely discussed by not only environmental experts, but also various economic researchers. It is increasingly mentioned by heads of state and finance ministers, as well as in joint statements by the G20 and discussed in the context of sustainable development and fight against environmental damage. The current increase in relevance of the green economy concept is undoubtedly fueled by growing disappointment in the most widespread economic model, as well as the feeling of fatigue generated by the many crises and environmental failures that have been observed during the first two decades of the new century. The transition to a green economy has a solid economic and social justification. Convincing arguments are emerging in favor of doubling the efforts of both the state and the private sector towards to green economy transformation. In this regard, the state is faced with the task of leveling the rules for green products by refusing to provide obsolete subsidies, reforming policies and creating new incentives, strengthening ecological infrastructure and economic mechanisms, redirecting public investment and moving to green public procurement.
\end{abstract}

\section{Introduction}

Over the past decade, humanity has simultaneously experienced several crises: the climate crisis, the crisis of biodiversity, the fuel, food, water, and in recent years the crisis of the financial system and the economy as a whole. An increase in global climate-changing emissions indicates a growing threat of rapid climate change, which could lead to disastrous consequences for humanity. Fluctuations in fuel prices and related fluctuations in food and commodity prices indicate structural weaknesses and risks that remain unresolved. Unstable demand projected by the International Energy Agency and other organizations implies continued dependence on oil and other fossil fuels, and a significant instability in energy prices at a time when the global economy is seeking recovery and growth [1].

\footnotetext{
* Corresponding author: ktyf110372@,rambler.ru
} 
Regarding the issue of food security, there is a lack of public understanding of the nature of the problem and of global joint decisions aimed at providing food for the 9 billion people who will inhabit the Earth in 2050 [2]. The lack of fresh water is already a global problem, and, according to forecasts, by 2030 there will be a growing gap between the annual demand for fresh water and its supplies from renewable sources [3]. The likelihood of improved sanitation for more than 2.6 billion people remains low; 884 million people still do not have access to clean drinking water [4]. Together, these crises sharply reduce the ability of humanity to maintain an achieved standard of living throughout the world and achieve the Millennium Development Goals to reduce extreme poverty [5]. They exacerbate persistent social problems associated with job loss, socio-economic insecurity and poverty, and threaten social stability. Although the causes of these crises differ, there is some fundamental similarity between them, consisting in the irrational distribution of capital.

Over the past two decades, large sums of money have been invested in real estate, mining of fossil fuels and structured financial assets with embedded derivative financial instruments [6]. However, relatively few funds have been spent on developing "renewable" energy, improving energy efficiency, the public transport system, and developing sustainable agriculture, the protection of ecosystems and biodiversity, and the conservation of soil and water. In fact, most of the strategies for economic development and growth have encouraged the rapid accumulation of physical, financial, and human capital, but due to the excessive depletion of natural capital, natural resources and ecosystems have been sacrificed. As the global supply of natural resources is depleted (and the process of depletion is often irreversible), this model of development and growth adversely affects the well-being of current generations and creates huge environmental risks and problems for future generations. The recent numerous crises are very characteristic of this model. Existing rules and market incentives exacerbate this problem of inefficient distribution of capital, as companies are allowed to carry out activities that have important environmental and social consequences, often without any external accounting and control. The role of deliberate actions of regulatory authorities, policies and public investment as factors capable of changing the model of private investment is also increasingly recognized and proved by success stories from many regions of the world, especially from developing countries [7].

\section{Materials and Methods}

In the simplest sense, a green economy is an economy with low emissions of carbon compounds, efficiently using resources and meeting the interests of the whole society. In a green economy, revenue and employment growth is driven by public and private investment that reduces carbon emissions and pollution, improves energy and resource efficiency, and prevents the loss of biodiversity and ecosystem services [8]. These investments need to be catalyzed and supported through targeted public spending, policy reforms, and regulatory changes. Such a development path should preserve, increase and, where necessary, restore natural capital as an important economic asset and a source of public goods, especially for the poor, whose income and security depend on nature.

A well-designed regulatory system can determine rights and create incentives that trigger the transition to a green economy, as well as remove barriers to green investment. The regulatory system can govern the most harmful activities that are incompatible with sustainable development, either by setting minimum standards or by completely banning certain activities. In addition, an adequate regulatory system will reduce the risks of legislative changes and business risks and increase investor confidence in the markets. It is often better for companies to deal with clearly established and truly applicable standards than 
to work in conditions of uncertainty or unfair competition from those who do not comply with regulatory requirements. A good addition to government rules and regulations can be industry self-regulation and voluntary agreements between the government and companies, freeing government agencies from some of the information load and administrative costs. Sustainable public procurement can strengthen markets for sustainable goods and services. Public procurement accounts for a significant share of total government spending, in both developed and developing countries. For example, in South Africa and Brazil, this share is 35 and $47 \%$ of GDP, respectively. Using sustainable public procurement methods, the state can generate high and long-term demand for green goods and services [9].

This practice encourages companies to make longer-term investments in innovation, and manufacturers to cut the costs. In turn, this can contribute to the wider commercialization of "green" goods and services, creating conditions for sustainable consumption. For example, sustainable government procurement programs in Austria, Denmark, Finland, Germany, the Netherlands, Sweden, and the United Kingdom have reduced procurement-related carbon monoxide emissions by an average of $25 \%$ [9]. Public procurement also contributed to the formation in Europe of markets for "organic" food and beverages, low-fuel vehicles and "sustainable" timber. The priority of public investment and spending in areas that stimulate the "greening" of economic sectors is undeniable. Subsidies provided in the public interest or with a positive external effect can be a powerful incentive for the transition to a green economy [10].

Green subsidies, such as price support measures, tax incentives, direct grants and loan guarantees, can be applied for various purposes: 1) to quickly take measures to prevent freezing of funds in "volatile" assets and systems or the loss of valuable natural capital on which the existence of people depends; 2) ensuring the creation of a green infrastructure and the introduction of green technologies, especially those that provide significant financial or non-financial benefits that are difficult for private companies to achieve; 3) support for the "green" industries that are at the initial stage of development as part of the strategy of accumulating comparative advantages and stimulating long-term employment and growth. Tax incentives can encourage investment in a green economy and mobilize private capital. Such incentives can be oriented both to consumption, and to the production of goods or the provision of services.

Many countries also use the net metering method to stimulate renewable energy sources and small power producing. Using this method, the consumer receives a deduction from future electricity bills if the amount of electricity supplied to the national power system from a consumer generator running on renewable raw materials exceeds the amount of energy taken by the consumer from the system. Net accounting is widespread in the USA, and introduced in Mexico and Thailand [11]. Government spending should be limited in time. Once introduced, subsidies can be difficult to cancel, because recipients are financially interested in lobbying for their preservation. As a rule, the state tries to minimize its costs and, while developing subsidy programs, provides various control methods.

For example, sometimes the conditions of the program are regularly reviewed and agreed adjustments are made, and sometimes restrictions on general expenses are set, and it is clearly defined when the program is completed. An analysis by the International Energy Agency of subsidies for energy production from renewable sources showed that in a situation where the government wants to increase private investment in a particular sector, it is important that the support is stable and predictable, gives certainty to investors and is canceled in a timely manner to stimulate innovation [12]. For the state, the provision of subsidies in many cases entails significant economic and environmental costs. Artificially lowering commodity prices through subsidies leads to inefficiencies, large amounts of waste, and excessive consumption, 
resulting in premature shortages of valuable non-renewable resources or degradation of renewable resources and ecosystems.

Global subsidies to the fishing industry are valued at $\$ 27$ billion per year, while it has been proven that at least $60 \%$ of these subsidies are harmful to the entire industry and appear to be a key factor in overfishing [4]. The estimated economic loss from depletion of fish stocks is about $\$ 50$ billion per year - nearly half the cost of global seafood catch. Subsidies reduce the return on green investments. When, under the conditions of subsidies, a certain type of "unsustainable" activity becomes cheap or low-risk, the market attractiveness of investing in "green" alternatives decreases. In 2008, worldwide subsidies for fossil fuel consumption were estimated at $\$ 557$ billion by the United Nations Environmental Protection Team [9]. Another $\$ 100$ billion was subsidized by production. By artificially lowering the cost of using fossil fuels, such subsidies deter consumers and companies from adopting energy efficiency measures that would quickly pay off in the absence of these subsidies [1]. There is a consensus that such subsidies represent a significant barrier to the development of renewable energy technologies. A complete cessation of all subsidies for the consumption and production of fossil fuels by 2020 would reduce global demand for primary electricity by $5.8 \%$ and reduce greenhouse gas emissions by $6.9 \%$ [2].

A reform of the subsidy system is possible if it is carried out with the utmost attention to the poorest segments of the population. The removal of subsidies is a difficult task, given the presence of parties interested in maintaining them, but there are many examples of countries that have implemented such reforms [2]. Subsidies are sometimes justified by the fact that they are beneficial to poor households, but if this assistance is not targeted, the bulk of the funding often goes to high-income households. In this regard, the reform should be gradual and provide for short-term support measures. Such a reform strategy may include, inter alia, introducing targeted consumption subsidies for poor households or redirecting financing to sectors requiring public investment in the first place, such as health or education.

Tax and market instruments can be effective investment promotion tools. Significant price imbalances that exist often hinder green investments or their further growth. In a number of sectors of the economy, for example, in the field of transport, such negative external effects as environmental pollution, deterioration of health or decline in labor productivity, as a rule, are not reflected in costs, which reduces the attractiveness of the transition to more "sustainable" goods and services. A similar situation exists with waste: the price of goods made from waste and the disposal service, as a rule, does not reflect all the costs of processing and disposal of waste. The solution to this problem is to include these incidental costs in the price of the product or service, using the corrective tax, payment or fee, or, in some cases, other market-based instruments, such as permits with the right to sell. Taxes often provide good incentives for lower emissions, more efficient use of natural resources.

\section{Results and Discussion}

A shift towards a green economy may require the state to be able to analyze problems, identify opportunities, establish priority areas for intervention, mobilize resources, implement policies and measure progress. For example, environmental taxes have been successfully applied in a number of developing countries. However, the introduction and management of such taxes can be a daunting task, the solution of which will require strengthening the administrative capacities of a government. In order for the movement towards a green economy not to lose its momentum, authorities also need to be able to evaluate the progress made. Moreover, this requires the ability to develop indicators, collect 
data, analyze them and interpret the results so that they can be used in policy development.

To prepare the workforce for the transition of the economy to "green" status, training and continuing education programs are needed. The transition to a green economy, by its very definition, provides for a certain restructuring of the economy, and special measures may be required to ensure that this transition goes smoothly for the workers it touches. Some sectors will require assistance in moving workers to new jobs. For example, in the fishing industry, fishers may need to be trained in other professions; in particular, they can participate in the restoration of fish stocks. Investment in retraining the workforce may also be required. For example, in Germany, the renewable power industry is experiencing a shortage of skilled workers [12]. In fact, the lack of skilled workers is felt in almost all sub-sectors of the energy sector, especially in hydropower and the energy use of biogas and biomass. An equally acute shortage of personnel is observed in engineering for the needs of renewable energy; especially lacking engineers, operators and maintenance specialists, as well as enterprise managers.

The active participation of governments in international processes can contribute to concerted action and cooperation in the transition to a green economy. The summit of the UN Conference on Sustainable Development (Rio +20 ), which will be held in 2012, will provide the international community with the most valuable opportunity to support the steps towards the transition to a green economy, given that one of the two themes of the summit will be "green economy in the context of sustainable development and poverty eradication." [2] In the next two years, it will depend on the participation and actions of state authorities, business, international organizations and other interested parties whether the summit will give a new impetus and direction to efforts to transition to a green economy. In preparation for accelerating the adoption of measures for the transition to a green economy at the national level, the United Nations Environmental Management Group, with the assistance of 32 international organizations, is preparing an internal project to evaluate how the experience of various UN agencies, funds and programs can be used directly to support countries in the transition to a green economy with low carbon emissions.

The international trade system can have a significant impact on activities in the green economy, facilitating or hampering the migration of green goods, technologies and investments. With the right prices for environmental resources at the national level, the international trade system allows countries to sustainably use their comparative advantages in providing natural resources for the benefit of both exporting and importing countries. For example, water-poor regions can ease the burden on local stocks by importing waterintensive products from more water-rich regions. As already noted, trade-related measures, such as standardization, can also play an important role in stimulating growth in a number of sectors of the green economy. On the other hand, such measures can also be perceived by countries as an obstacle to market access or as a form of trade protectionism. Therefore, it is extremely important that countries successfully combine and find the optimal balance between measures to protect the environment and measures to ensure market access.

\section{Conclusion}

Summing up, we can say that the green economy appreciates and invests in natural capital. Better conservation of ecosystem services enhances social security and increases household incomes in poor rural communities. Environmentally friendly farming methods significantly increase productivity in non-commodity farms. Finally, improving the availability of fresh water and sanitation and innovations in the field of decentralized energy supply (solar energy, biomass plants, etc.) also help to alleviate poverty as part of a green economy strategy. 


\section{References}

1. R. Kamaeva, T. Kvasnikova, M. Egorova, L .Kashapova, Opcion, 35:23, 563-580 (2019)

2. A.L. Spesivtsev, E.V. Aristova, M.V. Pluzhnik, M.S. Egorova, N.V. Varlacheva, Mediterranean Journal of Social Sciences, 6:2S4, 35-46 (2015)

3. E. Dotsenko, N. Ezdina, S. Mudrova, E3S Web Conf., 41, 04050 (2018)

4. E. Boretsky, M. Egorova, IOP Conference Series: Materials Science and Engineering, 132:1, 012018 (2016)

5. S. Zhironkin, O. Aleshina, V. Gorev, Y. Gunyakov, O. Zhironkina, E3S Web Conf., 105, 04001 (2019)

6. S. Zhironkin, S. Demchenko, G. Kayachev, E. Taran, O. Zhironkina, E3S Web of Conferences, 105, 03008 (2019)

7. V.A. Korkachev, A.G. Koryakov, Economics and Innovation Management, 3, 78-87 (2019) DOI: 10.26730/2587-5574-2019-3-78-87

8. A.L. Volkova, O.U. Korneva, Economics and Innovation Management, 2, 32-38 (2019) DOI: $10.26730 / 2587-5574-2019-2-32-38$

9. M. Egorova, O. Garanina, S. Petrova, I. Okhrimenko, Opcion, 35:22, 1446-1474 (2019)

10. T.V. Kiseleva, V.G. Mikhailov, Economics and Innovation Management, 4, 70-78 (2018). DOI:10.26730/2587-5574-2018-4-70-78

11. E.V. Shavina, Economics and Innovation Management, 3, 4-13 (2019) DOI: 10.26730/2587-5574-2019-3-4-13

12. E.V. Shavina, Economics and Innovation Management, 2, 18-31 (2019) DOI: 10.26730/2587-5574-2019-2-18-31 